\title{
Effect of Two Different Bleaching Concentrations on Enamel Color Stability and Surface Roughness: an in Vitro Study
}

\author{
Amr Khaled Mostafa ${ }^{1 *}$, Mohamed Riad Farid ${ }^{2}$, Maha A ElBaz ${ }^{3}$ and Rasha Ramadan Basheer ${ }^{4}$ \\ ${ }^{1}$ Department of Conservative Dentistry, Modern Science and Arts University, Egypt \\ ${ }^{2}$ Department of Conservative Dentistry, Cairo University, Egypt \\ ${ }^{3}$ Department of Conservative Dentistry, Cairo University, Egypt \\ ${ }^{4}$ Department of Conservative Dentistry, Modern Science and Arts University, Egypt
}

Submission: April 28, 2017; Published: May 25, 2017

*Corresponding author: Amr Khaled Mostafa, Department of Conservative Dentistry, Modern Science and Arts University, 102 Bashayer District Giza, Egypt, Tel: 01064451019; Email:amr.khaled.m@dentistry.cu.edu.eg

\begin{abstract}
Introduction: This in-vitro study was designed to investigate bleaching with two different concentrations of hydrogen peroxide on human enamel surfaces concerning surface roughness and color stability.
\end{abstract}

Materials and methods: A total number of 60 specimens that were prepared from extracted human anterior teeth were used in this study. The specimens were randomly divided to two equal groups according to the bleaching agent; $30 \%$ hydrogen peroxide (GI) and $38 \%$ hydrogen peroxide (GII) then evaluated for surface roughness and color measurements immediately. They were then subdivided into three groups according to the solution where it will be immersed as a referred to Cola, B referred to black tea and C referred to artificial saliva. Specimens were kept in an incubator at 37 degrees celcius and their color was evaluated at 24 and 48 hours.

Results: The results showed a significant increase in surface roughness of the bleached samples compared to the baseline measurements. However, there was no significant difference between the samples of the two bleached groups concerning surface roughness. Color evaluation both bleaching agents showed a significant whitening effect compared to the baseline where the $30 \%$ hydrogen peroxide was more significant on immediate measurement. After immersion in cola, black tea and saliva, there was no significant difference between the two groups anymore while there was a significant relapse in color in both the black tea and cola immersions with the effect of black tea being more pronounced.

Conclusion: Bleaching agents can cause surface alterations and should therefore be used with caution.

Keywords: Artificial saliva, Fluoride potential, pH value, remineralisation

\section{Introduction}

Dental bleaching is a well-known esthetic procedure that aims to lighten the color of discolored teeth. While it is one of the conservative solutions for tooth discoloration, the bleaching industry has risen significantly since its evolution [1-4]. The process involves the application of a bleaching material on the tooth surface with subsequent activation by chemical, light or lasers. Hydrogen peroxide is the main component of mostbleaching agents and is either supplied directly as hydrogen peroxide or as a product of a reaction that occurs between carbamide peroxide and sodium perborate [5].

The mechanism of bleaching was proposed differently in literature. A common belief is that chromophores which are organic compounds of conjugated chains bonded together by alternating single or double bonds affect tooth color negatively. It was stated that hydrogen peroxide can cause destruction of one or more bonds in the chains or cause oxidation to these chromophores to give lighter colors [6]. However, another perception stated that hydrogen peroxide can cause destruction of some crystalline structures in enamel which causes more light refraction and in turn, a lighter color perception [7]. The controversies run further as some authors believe that bleaching occurs primary in enamel and that it lightens the tooth color by masking the underlying dentin while others attribute the color change to the bleaching effect on the underlying dentin [8]. 


\section{Materials and Methods}

\section{Materials}

i. $\quad$ Dash In-Office Teeth whitening agent 30\% HP \& Dash ACP Relief (Discus Dental, LLC, LA, CA, USA)

ii. Pro Whitening Kit 38\% HP, Pro Whitening Kit Activator \& Pro Whitening Kit Desensitizing Gel (Beaming White, LLC Vancouver, WA, USA)

iii. Artificial Saliva

iv. Coca- Cola (Coca-Cola, Egypt)

v. Black Tea (Lipton, Unilever, UK)

\section{Methods}

Teeth selection: A total of 60 human anterior permanent teeth extracted for periodontal reasons were selected for this study. The crowns of the teeth were separated from their roots by means of a diamond disc then the pulpal tissues were removed from the pulp chamber by means of a periodontal curette. The crowns obtained were individually embedded in self-curing acrylic resin with the buccal surfaces facing upwards and thereby exposed for different applications. The surfaces were then polished by a rubber cup and a fluoride-free polishing paste (Prophy Paste, PSP Dental Company, Kent, UK).

Samples grouping: A total of number of 60 samples were randomly divided into two equal groups $(\mathrm{N}=30)$, according to the bleaching material used. GI referred to the group bleached by $30 \%$ hydrogen peroxide where GII referred to the group bleached by $38 \%$ hydrogen peroxide. Each group was further divided into three subgroups according to the storage medium. Group A were stored in Cola (Coca Cola, Egypt), groups B were stored in tea (Lipton Extra Strong, Unilever, London, UK) while groups C were stored in artificial saliva.

\section{Bleaching treatment}

A. $\quad 30 \%$ Hydrogen peroxide: The Whitening accelerator swabs were applied to the enamel surfaces. Then the whitening gel was applied with a thickness of 1-2 mm according to the manufacturer's instructions. The session continued for 15 minutes before the gel was removed by suction and gauze then the whole process was repeated again. The procedure was done for three sessions with a total bleaching time of 45 minutes. The ACP gel provided was then applied to the surfaces according to the manufacturer's instructions.

B. $\quad 38 \%$ Hydrogen peroxide: Both tips of the whitening gel and activator syringes were screwed together. The gels were pushed back and forth for more than 25 times as instructed by the manufacturer. The gel was then applied to the enamel surfaces and left for 15 minutes. The session lasted for 15 minutes before the gel was removed by suction and gauze then the process was repeated for two more sessions. The total bleaching time for this group was 45 minutes. The desensitizing and remineralizing gel was then applied to the surface according to the manufacturer's instructions.

C. Storage of samples: All teeth were kept in artificial saliva for 48 hours. Each group of teeth was then divided into three subgroups where each subgroup was directed to a different solution. The teeth were kept in an incubator (Shel lab, Sheldon Manufacturing, Inc. Cornelius, OR, USA) at 37 degree celcius for 24 hours, and then 5 teeth of each group were taken for color evaluation. The rest of the teeth were left immersed for a total of 48 hours, and then were taken for color evaluation [9].

\section{Testing procedures}

A. Surface roughness measurement: Surface roughness evaluation was done using a non-contact optical profilometer (ZYGO Maxim-GP 200) at baseline and after bleaching. This general purpose profilometer is used for three dimensional measurements of microstructures and surface topographies. It utilizes computerized phase stepping interferometry together with scanning white light interferometry that are analyzed by a software to provide measurements for areas, profiles or step heights.

B. Color measurements: The apparatus used in measurements is Cary 5000 Spectrophotometer provided from Agilent Technologies (USA). It is a double beam direct ratio recording system. It consists of the photometer unit and a PC computer. The optical system of the photometer unit includes a double monochromator of grating to grating type. The light beam from a tungsten halogen lamp after passing through the double monochromator (to be monochromatic) is chopped by a chopper mirror into the sample beam and reference beam, and then passes through the sample compartment to the detector. The light beam is detected by a photomultiplier which is sensitive to the visible/ ultraviolet region.

Statistical analysis: Numerical data were explored for normality by checking the distribution of data and using tests of normality (Kolmogorov-Smirnov and Shapiro-Wilk tests). Surface roughness $(\mathrm{Ra})$ data showed non-parametric distribution while color change data $(\Delta \mathrm{E}, \Delta \mathrm{L}, \Delta \mathrm{a}$ and $\Delta \mathrm{b})$ showed parametric distribution. Data were presented as mean, median, standard deviation (SD), minimum, maximum and 95\% Confidence Interval (95\% CI) for the mean values. For non-parametric data, MannWhitney U test was used to compare between the two bleaching agents. Wilcoxon signed-rank test was used to study the changes in Ra after bleaching. For parametric data, three-way ANOVA test was used to compare between the bleaching agents, storage media as well as immersion times. Tukey's post-hoc test was used for pair-wise comparisons when ANOVA test is significant. The significance level was set at $\mathrm{P} \leq 0.05$. Statistical analysis was performed with IBM SPSS (SPSS Inc., IBM Corporation, NY, USA) Statistics Version 20 for Windows. 


\section{Results}

The results showed a significant increase in surface roughness of the bleached samples compared to the baseline measurements. Within each group, there was a statistically significant increase in mean Ra after application as Group I scored a mean value of $0.605 \mu \mathrm{m}$ before application and $0.719 \mu \mathrm{m}$ after application. Group II scored a mean value of $0.359 \mu \mathrm{m}$ before application and $0.530 \mu \mathrm{m}$ after application. Both groups revealed a P-value of 0.012 which was statistically significant at $\mathrm{P} \leq 0.05$ (Table 1 and Figure $1 \& 2$ ).

Table 1: The mean, standard deviation (SD) values of Mann-Whitney $U$ tests for comparison between $\mathrm{Ra}(\mu \mathrm{m})$ and \% changes in Ra after using the two bleaching agents.

\begin{tabular}{|c|c|c|c|c|c|}
\hline \multirow{2}{*}{ Application } & \multicolumn{2}{|c|}{$\mathbf{3 0 \%} \mathbf{H 2 0 2}$} & \multicolumn{2}{|c|}{$\mathbf{3 8 \%} \mathbf{H 2 0 2}$} & \multirow{2}{*}{$\begin{array}{c}\text { P- } \\
\text { value }\end{array}$} \\
\cline { 2 - 5 } & Mean & SD & Mean & SD & 0.344 \\
\hline $\begin{array}{c}\text { Before } \\
\text { application }\end{array}$ & 0.605 & 0.43 & 0.359 & 0.239 & 0.301 \\
\hline $\begin{array}{c}\text { After } \\
\text { application }\end{array}$ & 0.719 & 0.494 & 0.53 & 0.26 & 0.401 \\
\hline \% change & 23.4 & 12 & 60.8 & 37.5 & 0.074 \\
\hline
\end{tabular}
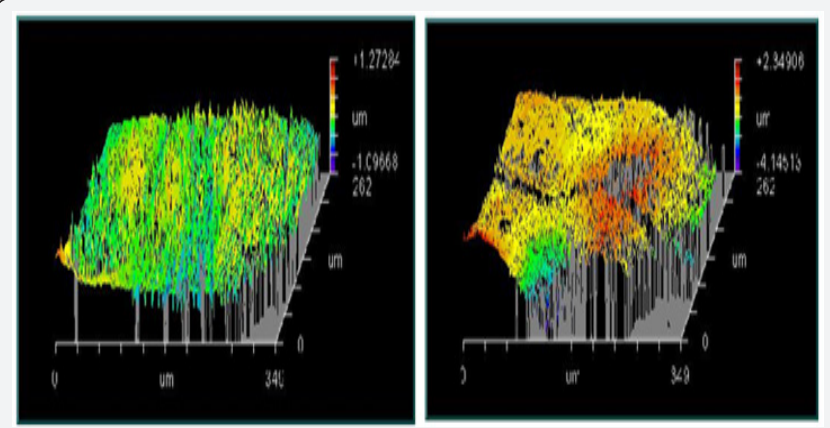

Figure 1: 3d images of Surface Roughness before (left) and after bleaching (right) in Group 1.
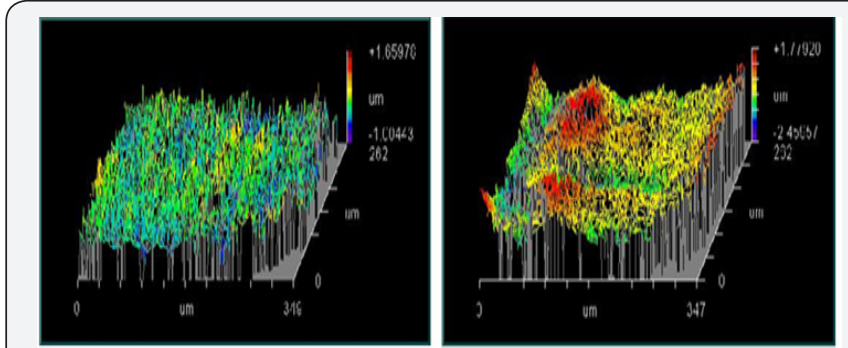

Figure 2: 3d images of Surface Roughness before (left) and after bleaching (right) in Group2.

Color evaluation revealed that immediately after bleaching (Before immersion), $30 \% \mathrm{H}_{2} \mathrm{O}_{2}$ agent showed statistically significantly higher mean $\Delta \mathrm{E}$ at 4.75 compared to the $38 \% \mathrm{H} 2 \mathrm{O} 2$ agent at 3.89. When immersed in cola $30 \% \mathrm{H}_{2} \mathrm{O}_{2}$ scored a mean value of 3.74 and 4.57 while $38 \% \mathrm{H}_{2} \mathrm{O}_{2}$ scored 3.8 and 4.48 for 24 and 48 hours respectively. When stored in black tea, $30 \% \mathrm{H}_{2} \mathrm{O}_{2}$ scored a mean value of 5.10 and 6.30 while $38 \% \mathrm{H}_{2} \mathrm{O}_{2}$ scored mean values of 5.22 and 6.50 for 24 and 48 hours respectively. As for artificial saliva immersion, $30 \% \mathrm{H}_{2} \mathrm{O}_{2}$ had a mean value of 0.57 and 0.70 while $38 \% \mathrm{H}_{2} \mathrm{O}_{2}$ had mean values of 0.65 and 0.67 for 24 and 48 hours of immersion respectively. There was no significant difference between the two bleaching agents when comparing the three subgroups. Comparing the three storage media, As regards $30 \% \mathrm{H}_{2} \mathrm{O}_{2}$ group, black tea showed the statistically significantly highest mean $\Delta \mathrm{E}$ at 5.10 and 6.30 after 24 and 48 hours respectively. Cola showed statistically significantly lower mean value at 3.74 after 24 hours and 4.57 after 48 hours. Artificial saliva showed the statistically significantly lowest mean $\Delta \mathrm{E}$ at 0.57 and 0.70 after 24 and 48 hours respectively. Similarly for 38\% H2O2 group, black tea showed the statistically significantly highest mean $\Delta \mathrm{E}$ at 5.22 and 6.50 after 24 and 48 hours respectively. Cola showed statistically significantly lower mean value at 3.80 and 4.48 after 24 and 48 hours respectively. Artificial saliva showed the statistically significantly lowest mean $\Delta \mathrm{E}$ at 0.65 after 24 hours and 0.67 after 48 hours (Table 2).

Table 2: The mean, standard deviation (SD) values of three-way ANOVA and Tukey's test for comparison between $\Delta \mathrm{E}$ of the two bleaching agents.

\begin{tabular}{|c|c|c|c|c|c|c|}
\hline & & $30 \% \mathrm{H}_{2} \mathrm{O}_{2}$ & & \multicolumn{2}{|c|}{$38 \% \mathrm{H}_{2} \mathrm{O}_{2}$} & \multirow{2}{*}{ P-value } \\
\hline Storage & Time & Mean & SD & Mean & SD & \\
\hline \multirow{3}{*}{ Artificial saliva } & $\begin{array}{l}\text { After bleaching } \\
\text { (Before }\end{array}$ & 4.75 & 0.37 & 3.89 & 0.31 & $<0.001^{*}$ \\
\hline & 24 hours & 0.57 & 0.08 & 0.65 & 0.26 & 0.508 \\
\hline & 48 hours & 0.7 & 0.14 & 0.67 & 0.14 & 0.781 \\
\hline \multirow{2}{*}{ Cola } & 24 hours & 3.74 & 0.45 & 3.8 & 0.31 & 0.807 \\
\hline & 48 hours & 4.57 & 0.27 & 4.48 & 0.27 & 0.62 \\
\hline \multirow{2}{*}{ Black tea } & 24 hours & 5.1 & 0.22 & 5.22 & 0.42 & 0.58 \\
\hline & 48 hours & 6.3 & 0.34 & 6.5 & 0.44 & 0.437 \\
\hline
\end{tabular}




\section{Discussion}

In this study, two bleaching agents with different concentrations were evaluated in respect to their effect on the surface roughness, color change and color stability on human enamel. Although the two materials used in this study are chemically activated, however, they have two different concentrations which 30\% hydrogen peroxide (Dash, Discus Dental, Culver City, CA, USA) and 38\% hydrogen peroxide (Pro-Whitening Kit, Beaming White, Vancouver, WA, USA). These high concentrations of hydrogen peroxide are considered for in-office use only. These two systems have identical bleaching session durations provided by the manufacturer, thus eliminating any chances that the bleaching time would affect our evaluation [10].

For surface roughness, Ushigome et al. [11] agreed with these results when he tested the effect of high and low concentrations of hydrogen peroxide on human enamel. They found a remarkable increase in surface roughness with higher concentrations and declared that higher concentrations of peroxides affected the enamel to a greater depth, although this only extended $5 \mu \mathrm{m}$ below the outermost surface layer. The results were also in accordance of Mendonça et al. [12] who conducted a study to detect superficial and subsurface changes of enamel after bleaching procedures. They found that bleaching induces superficial alterations to human enamel including a detectable increase in surface roughness. Abouassi et al. [10] also detected an increase in surface roughness of enamel when using higher concentrations of hydrogen peroxide. They pointed out to the fact that bleaching can affect the morphology of enamel which was explained by the oxidation and subsequent partial lysis of organic material within the enamel. An in-vivo study by Abdel Halim [13] was conducted on bovine incisors which were examined after sacrificing the animals also concluded that bleaching agents can cause surface alterations and referred the variability in results to the type of the applied bleaching agent. These findings were formerly explained by Markovic et al. [14] when they found similar results with bleaching as dissolution of the organic enamel surface layers (pellicle and cuticle) and loss of the aprismatic enamel layer after exposure to simulated long-term application of high-percentage hydrogen peroxide agents. Considering the $\mathrm{pH}$ of the products used, the 30\% hydrogen peroxide agent (Dash, Discus Dental, Culver City, CA, USA) had pH of 4.8 to 5.2 on activation while our $38 \%$ hydrogen peroxide agent (Pro-Whitening Kit, Beaming White, Vancouver, WA, USA) had a pH of 6.2 on activation. Xu et al. [15] found that bleaching agents cause more erosion and roughness to enamel surface as they become more acidic when it was found that the agents with $\mathrm{pH}$ values above 7 caused no alterations while the effect became more pronounce with lower $\mathrm{pH}$ values. However, this does not render the increase of surface roughness to the $\mathrm{pH}$ effect alone as it is worth noting that $38 \%$ hydrogen peroxide had a higher percentage increase on surface roughness values than $30 \%$ hydrogen peroxide despite having a higher $\mathrm{pH}$ value.

This might be explained by the effect of different remineralizing agents used as a post-treatment. Where the ACP (amorphous calcium phosphate) agent provided with the 30\% hydrogen peroxide product could be more effective than the sodium fluoride that was provided by the $38 \%$ hydrogen peroxide agent. This was in accordance with De Abreu et al. [16] who declared that ACP had a great effect on hydrogen peroxide treated enamel with concentrations lower than $35 \%$. It was clarified that ACP increases calcium-binding sites and creates a state of calcium and phosphorus super saturation thus allowing more remineralization and restoring surface alterations. It was also proven that ACP was more effective in restoring eroded surfaces than sodium fluoride and that the calcium-fluoride layer it formed was not as effective in restoring enamel surfaces [17].

On the other hand, Faraoni-Romano et al. [18] conducted a study on bovine teeth where it was found that the increase in surface roughness was not significant after bleaching using a contact profilometer. This difference in results could be attributed to the different device used for evaluation or could be due to the fact that bovine teeth were used instead of human. Cadenaro et al. [19] also conducted an in-vivo study on human teeth where epoxy resin replicas were obtained from the bleached teeth and tested by a profilometer where the results revealed no change to surface roughness despite using a $38 \%$ hydrogen peroxide bleaching agent. This might be attributed to the transfer of the surface details first by an impression and then to the epoxy replica which might not give an accurate representation.

As for color evaluation, the results came in accordance with Matis et al. [20] who evaluated color changes and stability for eight bleaching agents. They found that some of lower concentrations of peroxide gave significantly higher results than the higher concentrations. The explanation provided was that for a bleaching agent to be more effective in whitening than another, the additional agents that were added to the mixture should catalyze the peroxide more efficiently as the concentration of the peroxide itself is not the critical factor that decides the outcome. Another explanation was found in a study by Sulieman et al. [21] when they concluded that peroxide concentration was not a crucial factor when the agent was placed for a sufficient time. And since the contact time in our study was that indicated by each manufacturer, other factors could play their roles in deciding the outcome. Braun et al. [22] also agreed with these results when they tested two different concentrations of peroxide on enamel color, it was concluded that higher peroxide concentrations can produce faster results but not superior to agents with lower concentrations when applied for sufficient time. This was also clarified by Cavalli et al. [23] who analyzed the degree of hydrogen peroxide decomposition of three bleaching agents. They found that hydrogen peroxide exhibited only $40 \%$ decomposition after 40 minutes and thus suggested that lowering the concentration of the applied hydrogen peroxide could give the desired effect with less promoted damage.

An important factor provided is the $\mathrm{pH}$ value of the agents used. As the $30 \%$ hydrogen peroxide product had a $\mathrm{pH}$ value of 4.8 compared to the 6.2 value of the $38 \%$ agent. This was in agreement with Xu et al. [15] who explained that bleaching agents 
with lower $\mathrm{pH}$ values can give lighter color effects on enamel due to the morphological changes they exhibit on enamel surfaces.

Other studies did not yield opposite results rather than differences stated as "non-significant". Sa et al. [24] denied the effect of different concentrations of hydrogen peroxide and $\mathrm{pH}$ values on the resultant color after bleaching and advised the use of bleaching agents with lower concentrations and less acidity. Bacaksiz et al. [25] also stated a non-significant difference in color change between different peroxide concentrations and referred the better color stability for higher concentrations on follow up.

Bleaching effects are expected to last for an acceptable period without noticeable changes. The indications provided by most manufacturers of bleaching agents demand that patients should avoid dark chromogenic food or beverage for at least 24 hours after bleaching. The regular consumption of dark chromogenic beverages can negatively affect the resultant color stability and enhance the process of relapse [26]. Therefore in this study, the samples were stored in staining solutions to test the probability and degree of relapse that are expected for patients with high consumption of cola and black tea.

As for staining after bleaching, our results came in agreement with Berger et al. [27] and Côrtes et al. [28] who explained that the increased surface roughness is reflected by the irregularities left by the action of peroxide agents. These irregularities along with the rate of water absorption which is due to increased permeability can enhance the accumulation of coloring pigments on the enamel surface. This also came in accordance with Horning et al. [29] who explained that hydrogen peroxide increases permeability by opening diffusion channels in enamel to carry oxygen molecules through to the dentin substrate. Pirolo et al. [30] also agreed with these results when he stored bleached dental specimens in cola and coffee, and suggested that the degree of staining is dependent on the type of chromogen. The higher chromogenic effect of black tea was explained by Young et al. [31] who stated that black tea contains a mixture of chromogens that are mainly composed of reddish brown colors that easily reflect yellow and reddish colors in visible light. This was confirmed by Téo et al. [26] who found that black tea caused more color relapse than cola in a study that used the same products used in this study. The effect of cola drinks was also reflected in a study by De Araújo et al. [32] who concluded that acidic beverages with chromogenic potentials can cause deleterious effects to bleached enamel surfaces regarding surface roughness and color relapse. Alaghemand et al. [33] tested the effect of ACP application on bleached enamel regarding the prevention of tea staining after bleaching and found that ACP was not able to prevent enamel from being stained which explains that in this study, there was no significant difference in color stability between the stained groups.

These results were opposed by other studies such as a study conducted by Mori et al. [34] who observed the effect of coffee on bleached enamel and concluded that coffee had no effect on the bleaching effect.
The difference in these results might be due to the long storage time in saliva before beginning the staining process that was done for shorter periods than our study. Another proposal by Singh et al. [35] concluded that ACP was able to reduce the staining potential of tea on freshly bleached enamel but was not able to prevent it. This might also be due to the different staining protocol used in this study.

\section{Conclusion}

Under the limitations of the current study, it can be concluded that:

A. Both tested bleaching agents were successful in producing an acceptable lightening effect.

B. Bleaching agents can produce surface alterations, and therefore they should be used with caution.

C. Lower concentrations of peroxide can produce the desired effect with less alteration to the natural enamel.

D. Patient selection is a key factor for the bleaching effect to last for a longer time as staining solutions can produce a rapid color relapse.

\section{References}

1. Heymann HO, Swift EJ, Ritter AV (2013) Sturdevant's Art and Science of Operative Dentistry.

2. Hilton TJ, Ferracane JL, Broome J (2013) Fundamentals of Operative Dentistry: A Contemporary Approach. ( $4^{\text {th }}$ edn), Quintessence Pub Co, USA.

3. Chu SJ, Trushkowsky RD, Paravina RD (2010) Dental color matching instruments and systems. Review of clinical and research aspects. J Dent 38(Suppl 2): e2-e16.

4. Joiner A (2004) Tooth colour: a review of the literature. J Dent 32(1): 3-12.

5. Ribeiro AR, Fernanda JF, Boaventura JMC (2011) Evaluation of tooth color after bleaching with and without light-activation. Ativação por luz 26: $247-252$

6. Joiner A (2006) The bleaching of teeth: A review of the literature. J Dent 34(7): 412-419.

7. Yoshikawa M, Kakei M, Fujita M, Tanaka A, Suda N (2011) Misconceptions regarding tooth whitening by hydrogen peroxide. Bone 48(2): S116.

8. Sulieman M, Addy M, Macdonald E, Rees JS (2005) The bleaching depth of a $35 \%$ hydrogen peroxide based in-office product: a study in vitro. J Dent 33(1): 33-40.

9. Guler AU, Yilmaz F, Kulunk T, Guler E, Kurt S (2005) Effects of different drinks on stainability of resin composite provisional restorative materials. J Prosthet Dent 94: 118-124.

10. Abouassi T, Wolkewitz M, Hahn P (2011) Effect of carbamide peroxide and hydrogen peroxide on enamel surface: an in vitro study. Clin Oral Investig 15(5): 673-80.

11. Ushigome T, Takemoto $\mathrm{S}$, Hattori $\mathrm{M}$, Yoshinari M, Kawada E, et al. (2009) Influence of peroxide treatment on bovine enamel surface-cross-sectional analysis. Dent Mater J 28: 315-323.

12. Mendonça LC, et al. (2011) Permeability, roughness and topography of enamel after bleaching: Tracking channels of penetration with silver nitrate. Brazilian J Oral Sci 10: 1-6. 
13. Abdel Halim S (2012) Effect of Three Bleaching Agent on Surface Roughness of Enamel (In-vivo Study) Dentistry 02.

14. Markovic L, Jordan RA, Lakota N, Gaengler P (2007) Micromorphology of enamel surface after vital tooth bleaching. J Endod 33: 607-610.

15. Xu B, Li Q Wang Y (2011) Effects of $\mathrm{pH}$ values of hydrogen peroxide bleaching agents on enamel surface properties. Oper Dent 36(5): 554562 .

16. De Abreu DR, Sasaki RT, Amaral FLB, Florio FM, Basting RT (2011) Effect of home-use and in-office bleaching agents containing hydrogen peroxide associated with amorphous calcium phosphate on enamel microhardness and surface roughness. J Esthet Restor Dent 23(3): 158-168.

17. Carvalho FG, Brasil VL, Silva Filho TJ, Carlo HL, Santos RL (2013) Protective effect of calcium nanophosphate and CPP-ACP agents on enamel erosion. Braz Oral Res 27(6): 463-470.

18. Faraoni RJJ, Da Silveira AG, Turssi CP, Serra MC (2008) Bleaching agents with varying concentrations of carbamide and/or hydrogen peroxides: Effect on dental microhardness and roughness. J Esthet Restor Dent 20(6): 395-402.

19. Cadenaro M, Navarra CO, Mazzoni A, Nucci C, Matis BA, et al. (2010) An In Vivo Study of the Effect of a 38 Percent Hydrogen Peroxide In-office Whitening Agent on Enamel. J Am Dent Assoc 141(4): 449-454.

20. Matis BA, Cochran MA, Franco M, Al-Ammar W, Eckert GJ, et al. (2007) Eight In-office Tooth Whitening Systems Evaluated In Vivo: A Pilot Study. Oper Dent 32(4): 322-327.

21. Sulieman M, Addy M, MacDonald E, Rees JS (2004) The effect of hydrogen peroxide concentration on the outcome of tooth whitening: An in vitro study. J Dent 32(4): 295-299.

22. Braun A, Jepsen S, Krause F (2007) Spectrophotometric and visual evaluation of vital tooth bleaching employing different carbamide peroxide concentrations. Dent Mater 23(2): 165-169.

23. Cavalli V, Marson FC, Berger SB, Giannini M (2013) Color alteration and hydrogen peroxide decomposition of high-concentrated bleaching agents on enamel. Dent Mater 29(suppl 1): e37.

24. Sa Y, Chen D, Liu Y, Wen W, Xu M, et al. (2012) Effects of two in-office bleaching agents with different $\mathrm{pH}$ values on enamel surface structure and color: An in situ vs. in vitro study. J Dent 40(suppl 1): e26-e34.
25. Bacaksiz A, Tulunoglu 0, Tulunoglu I (2016) Efficacy and Stability of Two in-Office Bleaching Agents in Adolescents: 12 Months Follow-Up. J Clin Pediatr Dent 40(4): 269-273.

26. Téo TB, Takahashi MK, Gonzaga CC, Maria da Graça Kfouri Lopes (2010) Postbleaching color change evaluation of bovine teeth immersed in high-pigmentation potential solutions. RSBO 7(4): 401-405.

27. Berger SB, Coelho AS, Oliveira VAP, Cavalli V, Giannini M (2008) Enamel susceptibility to red wine staining after $35 \%$ hydrogen peroxide bleaching. J Appl Oral Sci 16(3): 201-204.

28. Côrtes G, Pini NP, Lima DA, Liporoni PC, Munin E, et al. (2013) Influence of coffee and red wine on tooth color during and after bleaching. Acta Odontol Scand 71(6): 1475-1480.

29. Horning D, Mongruel Gomes G, Fortes Bittencourt B, Manuel Ruiz L, Alessandra R, et al. (2013) Evaluation of human enamel permeability exposed to bleaching agents. Brazilian J Oral Sci 12(2): 114-118.

30. Pirolo R, Mondelli RFL, Correr GM, Gonzaga CC, Furuse AY (2014) Effect of coffe and a cola-based soft drink on the color stability of bleached bovine incisors considering the time elapsed after bleaching. J Appl oral Sci 22(6): 534-540.

31. Young N, Fairley P, Mohan V, Jumeaux C (2012) A study of hydrogen peroxide chemistry and photochemistry in tea stain solution with relevance to clinical tooth whitening. J Dent 40(2): e11-e16.

32. de Araújo LSN, dos Santos PH, Anchieta RB, Catelan A, Fraga Briso AL et al. (2013) Mineral loss and color change of enamel after bleaching and staining solutions combination. J Biomed Opt 18(10): 108004.

33. Alaghemand H, Hashemi Kamangar SS, Zarenegad N, Tabari N, Abedi H, et al. (2015) In-Vitro Effect of Casein Phosphopeptide Amorphous Calcium Phosphate on Enamel Susceptibility to Staining by Tea during Bleaching Treatment. J Dent (Tehran) 12(8): 607-613.

34. Mori AA, Lima FF, Benetti AR, Terada RS, Fujimaki M, et al. (2016) Susceptibility to coffee staining during enamel remineralization following the in-office bleaching technique: An in situ assessment. J Esthet Restor Dent 28(1): S23-S31.

35. Singh RD, Ram SM, Shetty O, Chand P, Yadav R (2010) Efficacy of casein phosphopeptide-amorphous calcium phosphate to prevent stain absorption on freshly bleached enamel: An in vitro study. J Conserv Dent 13(2): 76-79.

\section{Your next submission with Juniper Publishers} will reach you the below assets

- Quality Editorial service

- Swift Peer Review

- Reprints availability

- E-prints Service

- Manuscript Podcast for convenient understanding

- Global attainment for your research

- Manuscript accessibility in different formats

( Pdf, E-pub, Full Text, Audio)

- Unceasing customer service

Track the below URL for one-step submission

https://juniperpublishers.com/online-submission.php 